\title{
Female-biased sex ratio in the Asian corn borer, Ostrinia furnacalis: evidence for the occurrence of feminizing bacteria in an insect
}

\author{
DAISUKE KAGEYAMA, SUGIHIKO HOSHIZAKI* \& YUKIO ISHIKAWA \\ Laboratory of Applied Entomology, Department of Agricultural and Environmental Biology, Graduate School of \\ Agricultural and Life Sciences, The University of Tokyo, Yayoi, Bunkyo-ku, Tokyo 113-8657, J apan
}

\begin{abstract}
The maternally inherited, female-biased sex ratio in many arthropods has been attributed to infection with micro-organisms. Male killing, thelytoky and feminization are recognized as the mechanisms of the bacteria-induced sex ratio distortion in arthropods. A sex ratio distortion towards the female has been found in the Japanese population of the Asian corn borer Ostrinia furnacalis (Lepidoptera). In the present study, inheritance of the sex ratio distortion in the Asian corn borer and its underlying mechanism were investigated. Two of the 13 field-collected females produced all-female offspring. The female-biased sex ratio was maternally inherited for three generations. There was no difference in egg hatchability between thelygenic and normal crosses. Treatment with tetracycline for two generations resulted in production of only male offspring. Considering the sex determination system in lepidopteran insects, it was concluded that chromosomal males are feminized by a cytoplasmic agent(s), most probably parasitic bacteria. This is the first report of the occurrence of feminizing bacteria in insects. The sex ratio distorter was considered to occur at low frequency in the Asian corn borer population.
\end{abstract}

Keywords: feminization, Lepidoptera, maternal inheritance, micro-organisms, Ostrinia furnacalis, sex ratio.

\section{Introduction}

Distortion of the sex ratio towards the female has been repeatedly found in insects and crustaceans (Hurst, 1993; Hoy, 1994, pp. 267-300; Dunn et al., 1995). Most examples show maternal inheritance and are related to infection with cytoplasmic parasites.

Major mechanisms for over-production of female offspring (thelygeny), caused by cytoplasmic infection, can be mostly classified into three kinds: microbe-induced parthenogenesis that mainly produces females (thelytoky), selective death of males during the immature stages (male killing) and feminization of males (these were summarized in Hurst, 1993; Dunn et al., 1995).

Microbe-induced thelytoky is known only from parasitic wasps, and is caused by infection with bacteria of the genus Wolbachia (Stouthamer et al., 1993). Male killing has been found in many insects (Hurst \& Majerus, 1993; Groeters, 1996). In a

*Correspondence. E-mail: ahossy@hongo.ecc.u-tokyo.ac.jp number of insect species, male embryos, produced from a female infected with a sex ratio distorting agent, show a differentially high rate of mortality (early male killing, reviewed in Hurst, 1993). In mosquitoes infected with certain microsporidians, death of the males occurs during the fourth or later instar larvae (late male killing, Hurst, 1991). Various bacteria and microsporidians are known as the causal agents of the male killing trait (Hackett et al., 1986; Gherna et al., 1991; Hurst, 1991; Werren et al., 1994; Balayeva et al., 1995; Hurst et al., 1997). In contrast, feminization is known only from crustaceans. Infections with Wolbachia and microsporidians are known to cause the feminization in crustaceans (Legrand et al., 1987; Juchault et al., 1993; Dunn et al., 1995).

The reasons for the evolution of these behaviours in the parasites have been considered theoretically. In general, the female-biased sex ratio distortion is considered to be advantageous to the cytoplasmic genome because cytoplasmic genes are inherited asymmetrically from mother to offspring (Werren et al., 1988). Thelytoky and feminization are advanta- 
geous to sex ratio distorters because they lead to the production of more females, the sex through which they are transmitted. In the case of male killing, three potential advantages have been raised: resource allocation, avoidance of inbreeding and an increasing chance for horizontal transmission of a sex ratio distorter (Hurst, 1991; Hurst \& Majerus, 1993), although the actual advantages of male killing have not been confirmed to date (Hurst \& Majerus, 1993; Balas et al., 1996).

Female-biased sex ratios have been reported in the Japanese population of the Asian corn borer Ostrinia furnacalis (Lepidoptera: Pyralidae) (Miyahara, 1984). However, the inheritance and mechanism of the phenomenon have not been clarified. The objectives of the present study were to investigate the female-biased sex ratio in order to identify the inheritance and the underlying mechanism of the sex ratio distortion.

\section{Materials and methods}

Insects

The Asian corn borer, Ostrinia furnacalis, is a major pest of corn (maize) in eastern and south-eastern Asia. In Japan, five species of the $O$. furnacalis species complex (O. furnacalis, $O$. orientalis, $O$. scapulalis, $O$. zealis and $O$. zaguliaevi) occur (Mutuura \& Munroe, 1970). At Matsudo where the insects were collected, the five species probably occur sympatrically (Ishikawa, pers. obs.). It is difficult to identify species morphologically in the $O$. furnacalis complex, especially with respect to females (Mutuura \& Munroe, 1970). In the present study, female sex pheromones were used to identify $O$. furnacalis. Only $O$. furnacalis among the species complex has $(E)$ - and (Z)-12-tetradecenyl acetates as female sex pheromone components (Ando et al., 1980).

At first, female moths of the $O$. furnacalis complex were collected in the field at Matsudo $\left(35.8^{\circ} \mathrm{N}\right.$, $169.9^{\circ} \mathrm{E}$, Chiba Prefecture) in June 1996 without morphological identification of the species. They were brought to the laboratory and kept individually in clear plastic cups (diameter: $10 \mathrm{~cm}$; depth: $4.5 \mathrm{~cm}$ ). Most of them laid fertile eggs within a few days. The egg masses were kept in the plastic cups with an artificial diet (Silk Mate 2S, Nihon-Nosan, Yokohama). The number of eggs was counted under a binocular microscope. The egg hatch rates were determined from the numbers of emerging larvae, or from the number of unhatched eggs for the $F_{3}$ generation only. The diet was changed about once every 4 days. When they reached the prepupal stage, groups of 50 larvae were placed in a plastic cup (diameter: $12 \mathrm{~cm}$; depth: $6 \mathrm{~cm}$ ) with a piece of folded paper towel to facilitate pupation. The pupae were sexed by examination of the morphology of the abdominal tip under a binocular dissecting microscope, and then kept separately in plastic cups (diameter: $10 \mathrm{~cm}$; depth: $4.5 \mathrm{~cm}$ ). A piece of cotton soaked with $3 \%$ sucrose was provided for the adult moths. Insects were reared at $23^{\circ} \mathrm{C}$, under a light/ dark photocycle of 15L/9D.

A few females from each family were then subjected to sex pheromone analysis by gas chromatography.

\section{Crosses}

Each cross was performed in a plastic cup (diameter: $25 \mathrm{~cm}$; depth: $15 \mathrm{~cm}$ ) and involved three females and three males. Three days later, the females were transferred into new cups for oviposition. Only the crosses which successfully produced offspring were analysed.

\section{Treatment with tetracycline}

In order to examine whether the causal agent(s) of the sex ratio distortion is a bacterium, larvae were treated with tetracycline. Tetracycline hydrochloride was mixed into the artificial diet at a concentration of $0.6 \mathrm{mg} / \mathrm{g}$ wet weight and fed to the larvae from the neonate stage.

\section{Results}

\section{Sex ratio distortion in broods from field-collected females}

Thirteen broods (M1-M13) were obtained from the females collected in the field at Matsudo. The sex ratio (represented as the proportion of males) of each family was compared to 0.5 with a chi-squared test (Table 1). Three families showed a significant distortion $(P<0.01)$. Two families, M9 and M11, were composed of only females. The M13 family showed a significantly low male ratio of 0.21 , and the other 10 families showed no significant deviation from 0.5 . The families from females other than the three thelygenic females were pooled, and maintained as the 'normal strain'.

\section{Sex ratio in the $F_{1}$ generation}

Females from the M9 and M11 families were crossed with males from the families with a normal sex ratio to produce the $F_{1}$ generation. Crosses were

(c) The Genetical Society of Great Britain, Heredity, 81, 311-316. 
Table 1 Proportion of males in each family produced by Ostrinia furnacalis females collected at Matsudo, Chiba Prefecture, Japan in June 1996

\begin{tabular}{llr}
\hline Family & Proportion male & $n$ \\
\hline M1 & 0.49 & 120 \\
M2 & 0.49 & 72 \\
M3 & 0.48 & 82 \\
M4 & 0.42 & 107 \\
M5 & 0.37 & 97 \\
M6 & 0.47 & 47 \\
M7 & 0.42 & 64 \\
M8 & 0.47 & 36 \\
M9 & $0.00^{*}$ & 89 \\
M10 & 0.44 & 77 \\
M11 & 29 \\
M12 & $0.00^{*}$ & 92 \\
M13 & 0.44 & 28 \\
\hline
\end{tabular}

$n$, number of pupae.

* Significantly different from 0.5 by chi-squared test $(P<0.01)$.

set up between females in the M9 family and males in the M4 and M7 families (these crosses were designated 9.4 and 9.7, respectively), and between females in the M11 family and males in the M13 family (11.13). In each of the three crosses, three females were allowed to mate and lay eggs in a plastic cup. Therefore, we were not able to determine the exact number of egg-laying females in each cross in this generation. Eggs in each cross were randomly divided into two groups; one group of offspring was reared on the regular diet and the other on the diet treated with tetracycline. All of the three crosses produced offspring with a low proportion of males (Table 2a). Treatment of the larvae

Table 2 Proportion of males in the $\mathrm{F}_{1}$ generation for tetracycline untreated (control) and treated families of Ostrinia furnacalis

\begin{tabular}{lcr}
\hline Cross & Proportion male & $n$ \\
\hline (a) Untreated & & \\
9.7 & 0.13 & 211 \\
9.4 & 0.24 & 29 \\
11.13 & 0.00 & 56 \\
(b) Tetracycline treated & & \\
9.7 & 0.15 & 109 \\
9.4 & 0.00 & 13 \\
11.13 & 0.00 & 111 \\
\hline
\end{tabular}

$n$, number of pupae.

(C) The Genetical Society of Great Britain, Heredity, 81, 311-316. with tetracycline for a generation did not cure the sex ratio distortion (Table $2 b$ ).

\section{Sex ratio and hatchability in the $F_{2}$ generation}

The cross between females in the 11.13 family and males from the normal strain, and the cross between females in the 9.4 and 9.7 families and males from the normal strain successfully produced the $F_{2}$ generation. In this generation, females were individually put into plastic cups and allowed to lay eggs. The three crosses again resulted in production of female-biased offspring (Table $3 b$ ). In contrast, the cross within the normal strain produced a brood which did not show a sex ratio significantly different from 0.5 (Table 3a).

Egg hatchability was between 0.69 and 0.92 for the four crosses, $11.13 \times$ Normal, $9.4 \times$ Normal, $9.7 \times$ Normal and Normal $\times$ Normal (Table 3a,b). There was no conspicuous difference in hatching rate among the four crosses.

\section{Effect of tetracycline treatment for two generations}

It was not until the $\mathrm{F}_{2}$ generation that the antibiotic treatment had an effect on the sex ratio. Only the cross of $11.13 \times$ Normal successfully produced offspring in the $F_{2}$ generation. Tetracycline treatment resulted in production of all-male offspring in the $F_{2}$ generation (Table $3 \mathrm{c}$ ). The egg hatch rates of the tetracycline-treated groups were not different from the untreated crosses, including the same cross of $11.13 \times$ Normal $($ Table $3 b, c)$.

\section{Discussion}

\section{Causal agent(s) of sex ratio distortion}

The female-biased sex ratio in the two families of M9 and M11 was inherited maternally for the subsequent two generations. Treatment with tetracycline for two generations strongly affected the distorted sex ratio, and treatment for a generation did not affect the sex ratio. The results of the present study indicate that the sex ratio distortion in the Asian corn borer is caused by a cytoplasmic agent(s), probably a bacterium, considering the recent findings that parasitic bacteria frequently affect arthropod sex ratios and that some of these bacteria are found to be related to rickettsial lineages (Breeuwer et al., 1992; Rousset et al., 1992; Stouthamer et al., 1993; Martin et al., 1994; Werren et al., 1994; Balayeva et al., 1995; see also Hurst et al., 1997). Assuming a bacterial sex ratio distorter(s), we can deduce that tetracycline treatment for only a generation may not 
Table 3 Egg hatch rate and proportion of males in the $F_{2}$ generation for tetracycline untreated and treated families of Ostrinia furnacalis

\begin{tabular}{lcccr}
\hline Cross & Replication & $\begin{array}{c}\text { Egg } \\
\text { hatch rate }\end{array}$ & $\begin{array}{c}\text { Proportion } \\
\text { male }\end{array}$ & $n$ \\
\hline (a) Normal strain & - & 0.74 & 0.42 & 31 \\
(b) Untreated & & & & \\
$11.13 \times$ Normal & - & 0.80 & 0.18 & 45 \\
$9.4 \times$ Normal & a & 0.72 & 0.00 & 15 \\
& b & 0.92 & 0.00 & 9 \\
$9.7 \times$ Normal & - & 0.71 & 0.00 & 81 \\
(c) Tetracycline treated & & & & \\
$11.13 \times$ Normal & a & 0.63 & 1.00 & 24 \\
& b & 0.63 & 1.00 & 59 \\
& $\mathrm{c}$ & 0.70 & 1.00 & 58 \\
& $\mathrm{~d}$ & 0.86 & 1.00 & 24 \\
& $\mathrm{e}$ & 0.84 & 1.00 & 50 \\
& $\mathrm{f}$ & 0.67 & 1.00 & 8 \\
\hline
\end{tabular}

$n$, number of pupae.

*The larvae were treated with tetracycline for two generations.

be enough to cure the presumed sex ratio distorter completely.

The family M13 contained a low proportion of males, whereas the families M9 and M11 contained only females (Table 1 ). The $\mathrm{F}_{1} \mathrm{~s}$ from the crosses 9.7 and 9.4, which were the matriarchal lineages derived from the female producing the all-female brood of M9, produced low proportions of males (Table $2 \mathrm{a}$ ). These might be attributed to incomplete vertical transmission of the sex ratio distorter.

\section{Mechanism of sex ratio distortion}

Mechanisms for the cytoplasmic sex ratio distortion in animals were reviewed by Hurst (1993) and Dunn et al. (1995); thelytoky, feminization of the chromosomal male, early and late male killing, maternal choice of $\mathrm{X}$ rather than $\mathrm{Y}$ sperm, meiotic drive and cytoplasmic incompatibility have all been recognized. Ishihara (1992) summarized the 11 cases of female-biased sex ratio distortion in lepidopteran insects. For most of them, male killing during the embryo (early male killing) was suggested as the mechanism (Hurst, 1993; Hurst \& Majerus, 1993). Such a deduction is mostly based on the observation that the egg hatchability in a strain with distorted sex ratio is about half of that in a normal strain.

We considered possible causes of the microbeinduced sex ratio distortion in the Asian corn borer. First, thelytoky is unlikely because no unfertilized egg (laid by virgin females) has ever hatched in our observations. Secondly, early male killing is also unlikely because of the following three lines of evidence: (1) the egg hatchability of the thelygenic and normal crosses was not different (Table $3 a, b$ ); (2) the egg hatchability was not affected by the antibiotic treatment for two generations although it affected the sex ratio (Table 3b,c); (3) the aberrant sex ratio would have been cured to 0.5 with tetracycline treatment, if early male killing was the case. The third line of evidence also suggests that late male killing, maternal choice of $\mathrm{X}$ rather than $\mathrm{Y}$ sperm or meiotic drive are unlikely as the underlying mechanism.

The present results are well explained by feminization of the genetic male. In general, sex chromosomes of lepidopteran insects are considered to be $\mathrm{ZZ}$ in males and $\mathrm{ZW}$ in females. It is reasonable, at present, to assume that the Asian corn borer also has the ZW-ZZ system of sex determination. Then, if the sex ratio distorter alters a chromosomal male (sex chromosomes ZZ) into a functional female, elimination of the sex ratio distorter with an antibiotic will lead a thelygenic female to produce only male progeny after crossing with a normal male. This expectation is in agreement with the present results (Table 3c). In some species of isopods, a cytoplasmic agent, a bacterium of the genus Wolbachia, forces the host animal that is a chromosomal male to develop as a reproductively functional female (Juchault et al., 1993; see also Martin et al., 1994). In the amphipod Gammarus duebeni, femini- 
zation by microsporidia is known although the normal sex determination in $G$. duebeni is not solely genetic (Dunn et al., 1995). As far as we know, however, the present study is the first to indicate the occurrence of feminization caused by a cytoplasmic factor(s) in insects.

\section{Sex ratio distorter prevalence in host population}

The sex ratio distorter is likely to occur at a low frequency, which was estimated as $0.23(3 / 13)$ with a standard error of 0.12 , in the Asian corn borer population in Matsudo. The sex ratio distortion was found in only two of the five geographical populations examined by Miyahara (1984). To date, three locations have been reported from Japan where the thelygenic female of the Asian corn borer occurs (Miyahara, 1984 and the present study). These findings suggest that the sex ratio distorter in the Asian corn borer is not restricted to a narrow geographical area but distributed around Japan at a low frequency. In some other cases of cytoplasmic sex ratio distortion, the causal agent is considered to occur at a rather low frequency within a host animal population (Niijima \& Nakajima, 1981; Hurst et al., 1993; Stouthamer \& Kazmer, 1994; Balas et al., 1996; however, see also Juchault et al., 1993).

In conclusion, the female-biased sex ratio distortion in the Asian corn borer is caused by cytoplasmic infection with microorganisms, and feminization of chromosomal males is the underlying mechanism. However, it should be evaluated whether the sex ratio distortion in the Asian corn borer populations involves the other mechanisms.

\section{Acknow ledgements}

This study was supported by grants-in-aid for scientific research from the Ministry of Education, Science and Culture of Japan (09839010 and 07306003). We thank Dr Sadahiro Tatsuki for continuous encouragement, and Dr Yong-Ping Huang and $\mathrm{Mr}$ Takuma Takanashi for their great help in the gas chromatography analyses and insect rearing.

\section{References}

ANDO, T., SAITO, O., ARAI, K. AND TAKAHASHI, N. 1980. $(Z)$ and (E)-12-Tetradecenyl acetates: sex pheromone components of oriental corn borer (Lepidoptera: Pyralidae). Agric. Biol. Chem., 44, 2643-2649.

BALAS, M. T., LEE, M. H. AND WERREN, J. H. 1996. Distribution and fitness effects of the son-killer bacterium in Nasonia. Evol. Ecol., 10, 593-607.
BALAYEVA, N. M., EREMEEVA, M. E., TISSOT-DUPONT, H., ZAKHAROV, I. A. AND RAOULT, D. 1995. Genotype characterization of the bacterium expressing the malekilling trait in the ladybird beetle Adalia bipunctata with specific Rickettsial molecular tools. Appl. Env. Microbiol., 61, 1431-1437.

BreeuWer, J. A. J., STOUTHAMER, R., BARnS, S. M., PElletIER, D. A., WEISBURG, W. G. AND WERREN, J. H. 1992. Phylogeny of cytoplasmic incompatibility microorganisms in the parasitoid wasp genus Nasonia (Hymenoptera: Pteromalidae) based on $16 \mathrm{~S}$ ribosomal DNA sequences. Insect Mol. Biol., 1, 25-36.

DUNN, A. M., HATCHER, M. J., TERRY, R. S. AND TOFTS, C. 1995. Evolutionary ecology of vertically transmitted parasites: transovarial transmission of a microsporidian sex ratio distorter in Gammarus duebeni. Parasitology, 111, S91-S109.

GHERNA, R. L., WERrEN, J. H., WEISBURG, W., COTE, R., WOESE, C. R., MANDELCO, L. AND BRENNER, D. J. 1991. Arsenophonus nasoniae gen.-nov., sp.-nov., the causative agent of the son-killer trait in the parasitic wasp Nasonia vitripennis. Int. J. Syst. Bacteriol., 41, 563-565.

GROETERS, F. R. 1996. Maternally inherited sex ratio distortion as a result of a male-killing agent in Spilostethus hospes (Hemiptera: Lygaeidae). Heredity, 76, 201-208.

HACKETT, K. J., LYNN, D. E., WILliAMSON, D. L., GINSBERG, A. S. AND Whitcomb, R. F. 1986. Cultivation of the Drosophila sex-ratio spiroplasma. Science, 232, 1253-1255.

HOY, M. A. 1994. Insect Molecular Genetics. Academic Press, London.

HURST, L. D. 1991. The incidences and evolution of cytoplasmic male killers. Proc. $R$. Soc. B, 244, 91-99.

HURST, L. D. 1993. The incidences, mechanisms and evolution of cytoplasmic sex ratio distorters in animals. Biol. Rev., 68, 121-193.

HURST, G. D. D. AND MAJERUS, M. E. N. 1993. Why do maternally inherited microorganisms kill males? Heredity, 71, 81-95.

HURST, G. D. D., MAJERUS, M. E. N. AND WALKER, L. E. 1993. The importance of cytoplasmic male killing elements in natural populations of the two spot ladybird, Adalia bipunctata (Linnaeus) (Coleoptera: Coccinellidae). Biol. J. Linn. Soc., 49, 195-202.

HURST, G. D. D., HAMMARTON, T. C., BANDI, C., MAJERUS, T. M. O., Bertrand, D. AND MAJERUS, M. E. N. 1997. The diversity of inherited parasites of insects: the malekilling agent of the ladybird beetle Coleomegilla maculata is a member of the Flavobacteria. Genet. Res., 70, $1-6$.

ISHIHARA, M. 1992. Persistence of females that produce only female progeny in Lepidoptera. Res. Pop. Ecol., 34, 331-347.

JUCHAUlt, P., RIGAUd, T. AND MOCQUARD, J. P. 1993. Evolution of sex determination and sex ratio variability in wild populations of Armadillidium vulgare (Latr.) (Crustacea, Isopoda): a case study in conflict resolution. 
Acta Ecologica, 14, 547-562.

LEGRAND, J. J., LEGRAND-HAMELIN, E. AND JUCHAULT, P. 1987. Sex determination in Crustacea. Biol. Rev., 62, 439-470.

MARTIN, G., GRUPPE, S. G., LAULIER, M., BOUCHON, D., RIGAUD, T. AND JUCHAULT, P. 1994. Evidence for Wolbachia spp. in the estuarine isopod Sphaeroma rugicada (Crustacea): a likely cytoplasmic sex ratio distorter. Endocytobiosis Cell Res., 10, 215-225.

MIYAHARA, Y. 1984. Abnormal sex ratio in Ostrinia furnacalis Guenée (Lepidoptera: Pyralidae). Jap. J. Appl. Ent. Zool., 28, 131-136 (in Japanese with English summary).

MutuUrA, A. AND MUNROE, E. 1970. Taxonomy and distribution of the European corn borer and allied species: genus Ostrinia (Lepidoptera: Pyralidae). Mem. Entomol. Soc. Can., 71, 1-112.

NIIJIMA, K. AND NAKAJIMA, K. 1981. Abnormal sex-ratio in Menochilus sexmaculatus (Fabricius). Bull. Fac. Agr. Tamagawa Univ., 21, 59-67.
Rousset, F., BOUChON, D., PINTUREAU, B., JUChault, P. AND SOlIGNAC, M. 1992. Wolbachia endosymbionts responsible for various alterations of sexuality in arthropods. Proc. R. Soc. B, 250, 91-98.

StOUthameR, R. AND KAZMER, D. J. 1994. Cytogenetics of microbe-associated parthenogenesis and its consequences for gene flow in Trichogramma wasps. Heredity, 73, 317-327.

STOUTHAMER, R., BREEUWER, J. A. J., LUCK, R. F. AND WERREN, J. H. 1993. Molecular identification of microorganisms associated with parthenogenesis. Nature, $\mathbf{3 6 1}$, $66-68$.

WERrEN, J. H., NUR, U. AND WU, C.-I. 1988. Selfish genetic elements. Trends Ecol. Evol., 3, 297-302.

WERREN, J. H., HURST, G. D. D., ZHANG, W., BREEUWER, J. A. J., STOUTHAMER, R. AND MAJERUS, M. E. N. 1994. Rickettsial relative associated with male-killing in the ladybird beetle (Adalia bipunctata). J. Bacteriol., 176, 388-394. 